\title{
Mathematical Model of Dynamic Behavior of Microbial Desalination Cells for Simultaneous Wastewater Treatment and Water Desalination
}

\author{
Qingyun Ping, ${ }^{\dagger, \|}$ Chenyao Zhang, ${ }^{\ddagger}, \|$ Xueer Chen, ${ }^{\ddagger}$ Bo Zhang, ${ }^{\S}$ Zuyi Huang, ${ }^{*} \ddagger$ and Zhen He* ${ }^{\dagger}$ \\ ${ }^{\dagger}$ Department of Civil and Environmental Engineering, Virginia Polytechnic Institute and State University, Blacksburg, Virginia 24061, \\ United States \\ ${ }^{\ddagger}$ Department of Chemical Engineering, Villanova University, Villanova, Pennsylvania 19085, United States \\ ${ }^{\S}$ Key Laboratory of Environmental Biotechnology, Research Center for Eco-Environmental Sciences, Chinese Academy of Science, \\ Beijing 100085, People's Republic of China
}

\section{Supporting Information}

\begin{abstract}
Microbial desalination cells (MDCs) are an emerging concept for simultaneous wastewater treatment and water desalination. This work presents a mathematical model to simulate dynamic behavior of MDCs for the first time through evaluating multiple factors such as organic supply, salt loading, and current generation. Ordinary differential equations were applied to describe the substrate as well as bacterial concentrations in the anode compartment. Local sensitivity analysis was employed to select model parameters that needed to be re-estimated from the previous studies. This model was validated by experimental data from both a bench- and a large-scale MDC system. It could fit current generation fairly well and simulate the change of salt concentration. It was able to predict the response of the MDC with time under various conditions, and also provide
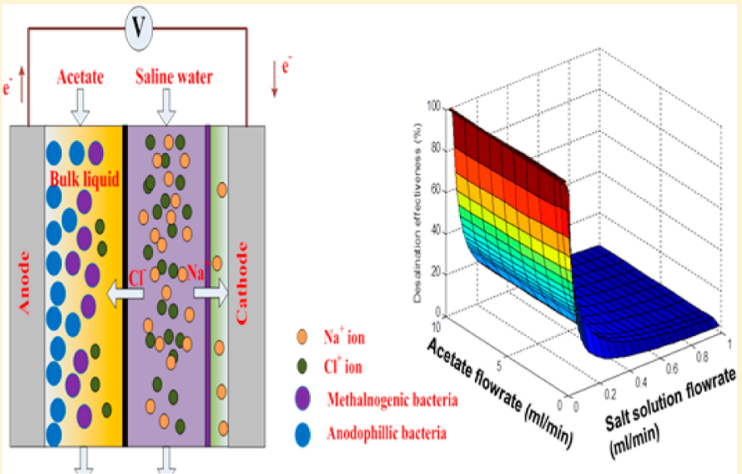
information for analyzing the effects of different operating conditions.

Furthermore, optimal operating conditions for the MDC used in this study were estimated to have an acetate flow rate of $0.8 \mathrm{~mL}$. $\min ^{-1}$, influent salt concentration of $15 \mathrm{~g} \cdot \mathrm{L}^{-1}$ and salt solution flow rate of $0.04 \mathrm{~mL} \cdot \mathrm{min}^{-1}$, and to be operated with an external resistor less than $30 \Omega$. The MDC model will be helpful with determining operational parameters to achieve optimal desalination in MDCs.
\end{abstract}

\section{INTRODUCTION}

Water shortage is a global issue that influences a large population, especially in the developing nations. ${ }^{1}$ To alleviate this problem, desalinating seawater or brackish water appears to be an effective approach to provide alternative source of fresh water. However, the high energy consumption associated with desalination processes makes desalinated water prohibitively expensive. For example, reverse osmosis (RO), which is the most widely applied desalination technology, requires $3-7 \mathrm{kWh}$ of energy to produce $1 \mathrm{~m}^{3}$ of freshwater. ${ }^{2}$ Recent development of the microbial desalination cell (MDC) provides a potentially energy-efficient desalination method. ${ }^{3,4}$ MDCs use electricity generated from low-grade substrates such as wastewater to drive the desalination process, so that it requires little external energy input (e.g., to drive pumping systems). Therefore, it holds great promise to significantly reduce energy consumption in desalination processes. MDC research is still in an early stage, and studies have been carried out to improve the understanding of MDCs by investigating the key factors, such as the anode organic loading rates, ${ }^{5}$ salt loading rates, ${ }^{6,7}$ external resistance, ${ }^{8,9}$ hydraulic retention time, ${ }^{9}$ new func- tions, ${ }^{10,11}$ membrane fouling, ${ }^{12,13}$ intermembrane distance, ${ }^{14}$ and system configuration. ${ }^{15}$

Given complex desalination processes and strong interactions between biological, electrochemical, and engineering factors in MDCs, a proper mathematic model will be essential for the optimization and the scaling up of MDCs. MDCs derive from microbial fuel cells (MFCs) by adding a third compartment between the anode and the cathode, separated by anion or cation exchange membranes for a new function of desalination. While several mathematical models exist for MFCs or microbial electrolysis cells (MECs), ${ }^{16-18}$ no model has been developed for MDCs. Most MFC/MEC models are based on the NernstMonod type of equations to quantify substrate consumption and bacterial growth. ${ }^{19-22}$ When it comes to mass transfer in an anode compartment, two types of approaches are usually employed. The first approach is based on the assumption of heterogeneous spatial distribution of substrates and micro-

Received: August 20, 2014

Accepted: October 15, 2014

Published: October 15, 2014 
organisms in both bulk liquid and biofilm, and quantified using partial differential equations. ${ }^{23}$ The second approach employs simplified ordinary differential equations, based on continuous stirred tank reactor (CSTR) model assuming ideal mixing in the anodic compartment and ignoring the concentration gradient within biofilm. ${ }^{19,24}$

On the basis of the MFC models, a mathematic MDC model was developed here. The model was calibrated using experimental data obtained from a lab-scale MDC upon the change of substrate flow rates, and validated by the data from the experimental conditions with different substrate concentrations, salt concentrations, and external electrical resistance. The validated model was then used to predict the performance of the MDC affected by either single or multiple operating parameters. The model was also validated by the experimental data from a large-scale MDC system (total liquid volume of 105 $\mathrm{L})$. To the best of our knowledge, this is the first mathematic model for MDCs.

\section{MATERIALS AND METHODS}

MDC Setup and Operation. The MDC reactor was constructed in tubular configuration similar to that in a previous study (Supporting Information, SI, Figure S1). ${ }^{4,8}$ It consisted of an inner tube made with anion exchange membrane (AEM, AMI-7001, Membrane International, Inc., Glen Rock, NJ) and an outer tube made of cation exchange membrane (CEM, CMI-7000, Membrane International, Inc.) The diameters of the $\mathrm{AEM}$ and the CEM tubes were 3.8 and $5.0 \mathrm{~cm}$, respectively, and the effective lengths of both tubes were $20 \mathrm{~cm}$, resulting in an anode liquid volume of $300 \mathrm{~mL}$ (including the liquid in the PVC caps and connectors) and a saline water volume of 150 $\mathrm{mL}$. The anode electrode was a $20 \mathrm{~cm}$ long carbon fiber brush, and the cathode electrode was a piece of carbon cloth coated with activated carbon supported platinum $(\mathrm{Pt} / \mathrm{C})$ as a catalyst at a loading rate of $0.2 \mathrm{mg} \mathrm{Pt} \mathrm{cm}^{-2} \cdot{ }^{25}$ Both electrodes were connected to an external circuit using titanium wire across 0.1 $\Omega$ unless indicated elsewhere. The anode feed solution contained (per $\mathrm{L}$ of tap water): sodium acetate, $1 \mathrm{~g}$ (unless stated otherwise); $\mathrm{NH}_{4} \mathrm{Cl}, 0.15 \mathrm{~g} ; \mathrm{NaCl}, 0.5 \mathrm{~g} ; \mathrm{MgSO}_{4}, 0.015 \mathrm{~g}$; $\mathrm{CaCl}_{2}, 0.02 \mathrm{~g} ; \mathrm{KH}_{2} \mathrm{PO}_{4}, 0.53 \mathrm{~g} ; \mathrm{K}_{2} \mathrm{HPO}_{4}, 1.07 \mathrm{~g}$; and trace element, $1 \mathrm{~mL} .^{26}$ The salt solution was prepared by dissolving $\mathrm{NaCl}$ into tap water. The catholyte was $50 \mathrm{mM}$ phosphate buffer solution, dripping from the top to the bottom of the outer tube for rinsing the cathode electrode at a recirculation rate of $35 \mathrm{~mL} \cdot \mathrm{min}^{-1}$. The feeding rates of the anolyte and the salt solution were $0.5 \mathrm{~mL} \cdot \mathrm{min}^{-1}$ (HRT of $10 \mathrm{~h}$ ) and $0.06 \mathrm{~mL}$. $\min ^{-1}$ (HRT of $1.7 \mathrm{~d}$ ), respectively (unless stated otherwise). In addition, the anolyte was recirculated at $100 \mathrm{~mL} \cdot \mathrm{min}^{-1}$.

Measurement and Analysis. The MDC voltage was recorded every $3 \mathrm{~min}$ using a digital multimeter (Keithley Instruments, Inc., Cleveland, OH, U.S.A.). The conductivity of the salt solution was measured using a benchtop conductivity meter (Mettler-Toledo, Columbus, OH, U.S.A.). The chemical oxygen demand (COD) was measured using a colorimeter according to the manufacture manual (Hach Company, Loveland, CO, U.S.A.). According to an established linear relationship between conductivity and $\mathrm{NaCl}$ concentration, the concentration of $\mathrm{NaCl}$ was calculated based on the measured conductivity.

Model Formulation. Mass Balances for Substrate, Microorganisms, and Electron Mediators in the Anode. The mass balance was established based on the assumption that microbial growth follows the multiplicative Monod kinetics. ${ }^{19,21}$
In addition, an intracellular redox mediator was assumed to be generated by anodophillic bacteria to aid the transfer of the electrons produced by the bacteria from the substrate, as suggested by a previous work of an MFC model. ${ }^{19}$ Ideal mixing in all three compartments of MDCs was assumed, thus ordinary differential equations could be used to quantify the concentrations of the substrate, anodophillic, and methanogenic microorganisms in the anode compartment. These differential equations were based on or modified from the previous study. ${ }^{19}$

The mass balance for the substrate is shown in eq 1 :

$$
\begin{aligned}
\frac{d S}{d t} & =D_{\text {anode }}\left(S_{\text {in }}-S\right)-k_{\mathrm{s}, \mathrm{a}, \max } \frac{S}{K_{\mathrm{a}}+S} \frac{M_{\mathrm{OX}}}{K_{\mathrm{M}}+M_{\mathrm{OX}}} C_{\mathrm{a}} \\
& -k_{\mathrm{s}, \mathrm{m}, \max } \frac{S}{K_{\mathrm{m}}+S} C_{\mathrm{m}}
\end{aligned}
$$

where $S$ is the concentration of the substrate $\left(\mathrm{mg}-\mathrm{S} \cdot \mathrm{L}^{-1}\right) ; S_{\text {in }}$ is the concentration of the influent substrate $\left(\mathrm{mg}-\mathrm{S} \cdot \mathrm{L}^{-1}\right) ; C_{\mathrm{a}}$ and $C_{\mathrm{m}}$ are the concentrations of anodophilic and methanogenic microorganisms $\left(\mathrm{mg}-\mathrm{C} \cdot \mathrm{L}^{-1}\right)$, respectively; $k_{\mathrm{s}, \mathrm{a} \text {,max }}$ and $k_{\mathrm{s}, \mathrm{m}, \text { max }}$ are the maximum substrate consumption rates by anodophilic and methanogenic microorganisms $\left(\mathrm{mg}-\mathrm{S} \cdot \mathrm{mg}^{-\mathrm{a}^{-1}} \cdot \mathrm{day}^{-1}\right)$, respectively; $M_{\mathrm{OX}}$ is the oxidized mediator fraction per anodophillic microorganism (mg-M.mg-a $\left.{ }^{-1}\right) ; K_{a}, K_{\mathrm{m}}$, and $K_{\mathrm{M}}$ are the halfsaturation concentrations for the anodophillic microorganisms, methanogenic microorganisms, and the redox mediator (mg-S. $\mathrm{L}^{-1}, \mathrm{mg}-\mathrm{S} \cdot \mathrm{L}^{-1}$, and $\mathrm{mg}-\mathrm{M} \cdot \mathrm{mg}^{-\mathrm{a}^{-1}}$ ), respectively. The growth of anodophillic bacteria, represented by the second term of eq 1 , was assumed to be limited by both substrate concentration and the oxidized form of the mediator, while the growth of methanogenic microorganisms, i.e., the last term of eq 1 , was assumed to be limited only by the substrate concentration. ${ }^{19}$ $D_{\text {anode }}$ is the dilution rate $\left(\right.$ day $\left.^{-1}\right)$ as defined in eq 2 .

$$
D_{\text {anode }}=\frac{Q_{\text {in }}}{V_{\text {anode }}}
$$

where $Q_{\text {in }}$ is the influent flow rate of the substrate $\left(\mathrm{L} \cdot \mathrm{day}^{-1}\right)$, and $V_{\text {anode }}$ is the volume of the anode compartment $(\mathrm{L})$.

The differential equations for the concentrations of anodophilic and methanogenic microorganisms in the anode compartment are shown below:

$$
\begin{aligned}
& \frac{d C_{\mathrm{a}}}{d t}= k_{\mathrm{a}} C_{\mathrm{a}}-k_{\mathrm{d}, \mathrm{a}} C_{\mathrm{a}}-D_{\mathrm{anode}} \\
& \frac{1+\operatorname{tahn}\left(k_{\mathrm{a}, \mathrm{x}}\left(C_{\mathrm{a}}+C_{\mathrm{m}}-C_{\mathrm{a}, \max }\right)\right)}{2} C_{\mathrm{a}} \\
& \frac{d C_{\mathrm{m}}}{d t}= k_{\mathrm{m}} C_{\mathrm{m}}-k_{\mathrm{d}, \mathrm{m}} C_{\mathrm{m}}-D_{\mathrm{anode}} \\
& \frac{1+\operatorname{tahn}\left(k_{\mathrm{m}, \mathrm{x}}\left(C_{\mathrm{a}}+C_{\mathrm{m}}-C_{\mathrm{m}, \max }\right)\right)}{2} C_{\mathrm{m}}
\end{aligned}
$$

where $k_{\mathrm{d}, \mathrm{a}}$ and $k_{\mathrm{d}, \mathrm{m}}$ are the decay rates of the microorganisms $\left(\right.$ day $\left.^{-1}\right) ; k_{\alpha, \mathrm{x}}$ and $k_{\mathrm{m}, \mathrm{x}}$ are the steepness factors for anodophillic microorganism $\left(\mathrm{L} \cdot \mathrm{mg}^{-\mathrm{a}^{-1}}\right)$ and methanogenic microorganisms $\left(\mathrm{L} \cdot \mathrm{mg}-\mathrm{m}^{-1}\right)$ for the biofilm retention; $C_{\alpha, \max }$ and $C_{\mathrm{m}, \max }$ are the maximum attainable concentrations for anodophillic microorganism $\left(\mathrm{mg}-\mathrm{a} \cdot \mathrm{L}^{-1}\right)$ and methanogenic microorganisms (mg$\left.\mathrm{m} \cdot \mathrm{L}^{-1}\right) ; k_{\mathrm{a}}$ and $k_{\mathrm{m}}$ are the growth rates of the microorganisms $\left(\right.$ day $\left.^{-1}\right)$ calculated by the eqs 5 and 6 : 


$$
\begin{aligned}
& k_{\mathrm{a}}=k_{\mathrm{a}, \max } \frac{S}{K_{\mathrm{a}}+S} \frac{M_{\mathrm{OX}}}{K_{\mathrm{M}}+M_{\mathrm{OX}}} \\
& k_{\mathrm{m}}=\mathrm{k}_{\mathrm{m}, \max } \frac{S}{K_{\mathrm{m}}+S}
\end{aligned}
$$

where $k_{\mathrm{a}, \max }$ and $k_{\mathrm{m} \text {,max }}$ are the maximum microorganism growth rates $\left(\right.$ day $\left.^{-1}\right)$.

The intracellular material balance for the oxidized mediator can be described as follows:

$$
\begin{aligned}
& \frac{d M_{\mathrm{OX}}}{d t}=-Y_{\mathrm{M}} k_{\mathrm{s}, \mathrm{a}}+\frac{\gamma}{V_{\text {anode }} C_{\mathrm{a}}} \frac{I_{\mathrm{MDC}}}{n_{\mathrm{e}} F} \\
& M_{\text {total }}=M_{\mathrm{OX}}+M_{\text {red }}
\end{aligned}
$$

where $M_{\text {total }}$ is the total mediator fraction per microorganisms $\left(\mathrm{mg}-\mathrm{M} \cdot \mathrm{mg}^{-\mathrm{a}^{-1}}\right) ; M_{\mathrm{red}}$ is the reduced mediator fraction per microorganisms $\left(\mathrm{mg}-\mathrm{M} \cdot \mathrm{mg}^{-\mathrm{a}^{-1}}\right) ; Y_{\mathrm{M}}$ stands for the mediator yield (mg-M-mg- $\left.\mathrm{S}^{1-}\right) ; \gamma$ is the mediator molar mass (mg-M. mole-M $\left.\mathrm{M}^{-1}\right) ; I_{\mathrm{MDC}}$ is the current through the circuit of MDCs (A); $F$ is the Faraday constant $\left(\mathrm{A} \cdot \mathrm{day} \cdot \mathrm{mol}^{-1}\right)$; and $n_{\mathrm{e}}$ is number of electrons transferred per mole of mediator (mole-e-mole$\left.\mathrm{M}^{-1}\right)$.

Mass Balance of Salt. Salt is removed from the saline solution mainly by ionic current between the anode and cathode of MDCs. In addition, salt diffuses into other compartments due to the concentration gradient. Ordinary differential equations shown below are developed to quantify the salt concentration:

$$
\begin{aligned}
& \frac{d C_{\text {salt, } \mathrm{m}}}{d t}=D_{\text {salt }} \cdot\left(C_{\text {salt,in }}-C_{\text {salt, } \mathrm{m}}\right)-d \cdot\left(C_{\text {salt, } \mathrm{m}}-C_{\text {salt, } \mathrm{a}}\right) \\
& -d \cdot\left(C_{\text {salt }, \mathrm{m}}-C_{\text {salt }, \mathrm{c}}\right)-\frac{I_{\mathrm{MDC}}}{F \cdot V_{\text {salt }}} \\
& \frac{d C_{\text {salt } \mathrm{a}}}{d t}=d \cdot\left(C_{\text {salt }, \mathrm{m}}-C_{\text {salt, } \mathrm{a}}\right)-D_{\text {anode }} \cdot C_{\text {salt,a }} \\
& \frac{d C_{\text {salt }, \mathrm{c}}}{d t}=d \cdot\left(C_{\text {salt }, \mathrm{m}}-C_{\text {salt }, \mathrm{c}}\right)
\end{aligned}
$$

where $C_{\text {salt,a }}, C_{\text {salt,m }}, C_{\text {salt,m }}$ and are the salt concentrations in the anode, the salt, and the cathode compartments (mol-salt $\cdot \mathrm{L}^{-1}$ ), respectively; $D_{\text {salt }}$ is the dilution rate $\left(\mathrm{day}^{-1}\right)$ in the salt compartment that is quantified by the ratio of the salt flow rate $\left(Q_{\text {salt }}\right)$ over the volume of the salt compartment $\left(V_{\text {salt }}\right) ; d$ is a membrane salt transfer coefficient that is equal to the ratio between the product of diffusion coefficient and membrane surface area and the product of the membrane thickness and the anode volume $\left(\right.$ day $\left.^{-1}\right)$.

The first term on the right-hand side of eq 9 represents the salt concentration retained in the middle compartment. The second and third terms represent the desalination due to the concentration-gradient driven diffusion from the salt compartment through ion exchange membranes to the anode and cathode, respectively. The last term of eq 9 quantifies the desalination via the salt ion migration driven by the ionic current and charge balance, which is described by the Faraday's law. Equation 10 describes the salt balance in the anode compartment in which the second term describes the salt lost in the anode effluent flow. Equation 11 quantifies the salt concentration in the cathode compartment. The change in the salt concentration due to water osmosis (dilution effect) was not considered in this model.

Current Generation. The overall cell voltage in MDCs is modeled by the following equation:

$$
\begin{aligned}
& I_{\mathrm{MDC}} R_{\text {ext }}=V_{\mathrm{OC}}-O P_{\text {anode }}-O P_{\text {cathode }}-O P_{\text {conc }} \\
& \quad-I_{\mathrm{MDC}} R_{\text {int }}
\end{aligned}
$$

where $R_{\text {ext }}$ is the external resistance $(\Omega) ; V_{\mathrm{OC}}$ is the open circuit voltage $(\mathrm{V}) ; \mathrm{OP}_{\text {anode }}$ is the anode overpotential $(\mathrm{V})$; $\mathrm{OP}_{\text {cathode }}$ is the cathode overpotential $(\mathrm{V}), \mathrm{OP}_{\text {conc }}$ is the concentration overpotential $(\mathrm{V}) ; R_{\text {int }}$ is the internal resistance of the cell $(\Omega)$ that is given in eq 13 and made up of mass transfer resistance, the ohmic resistance, and activation resistance. In particular, mass transfer resistance through the exchange membrane $R_{\text {membrane }}$ is estimated from experiment as $2.0 \Omega$ for our MDC system. ${ }^{12}$ The ohmic resistance includes the resistance of anolyte solution $R_{\text {anolyte }}(0.28 \Omega$ in this work), and the resistance of salt solution $R_{\text {salt }}(\Omega)$ (given by eq 14) which were obtained from integration according to the MDC's tubular configuration. The last two terms of eq 13 describe other internal resistance sources that are related to the bacterial growth (e.g., activation resistance).

$$
\begin{aligned}
R_{\text {int }}= & R_{\text {membrane }}+R_{\text {anolyte }}+R_{\text {salt }}+R_{\text {min }} \\
& +\left(R_{\text {max }}-R_{\text {min }}\right) \cdot e^{-k_{\mathrm{r}} \cdot C_{\mathrm{a}}} \\
R_{\text {salt }}= & \frac{1.2 \times 10^{-3}}{C_{\text {salt }, \mathrm{m}}}
\end{aligned}
$$

where $R_{\min }$ and $R_{\max }$ are the minimum and maximum internal resistances $(\Omega)$, and $k_{\mathrm{r}}$ is the constant that determines how fast the internal resistance respond to the change in microorganism concentration $C_{\mathrm{a}}\left(\mathrm{L} \cdot \mathrm{mg}^{-\mathrm{a}^{-1}}\right)$.

The dependence of cell voltage on the catalyst load suggests the exponential relationship between anodophilic microorganism concentration and the open circuit voltage: ${ }^{19}$

$$
V_{\mathrm{OC}}=V_{\min }+\left(V_{\max }-V_{\min }\right) \cdot e^{-1 /\left(k_{r} \cdot C_{a}\right)}
$$

where $V_{\min }$ and $V_{\max }$ are the lowest and highest observed $V_{\mathrm{OC}}$ values $(\mathrm{V})$.

It was assumed in this study that the anode overpotential and the cathode overpotential could be neglected because sufficient buffer solutions were used for both the anode and cathode, which eliminated the effect of the most influential parameter $(\mathrm{pH})$ on overpotential; ${ }^{27}$ and a cathode catalyst $\mathrm{Pt} / \mathrm{C}$ was used to ensure an efficient cathode reaction. Using this assumption and eq 12, the MDC current is calculated as follows:

$$
I_{\mathrm{MDC}}=\frac{V_{\mathrm{OC}}-\mathrm{OP}_{\text {conc }}}{\left(R_{\mathrm{ext}}+R_{\mathrm{int}}+R_{\mathrm{salt}}\right)}
$$

The concentration overpotential was assumed to be associated with electron mediators and could be modeled as follows: ${ }^{19}$

$$
\mathrm{OP}_{\text {conc }}=\frac{R T}{\mathrm{~F}} \ln \left(\frac{M_{\text {total }}}{M_{\text {red }}}\right)
$$

Sensitivity Analysis. Most model parameters in this study were based on the previous work. ${ }^{19}$ Parameter $k_{\mathrm{a}, \max }$ was estimated to 0.197 according to the average value of maximum growth rate of anaerobic culture. ${ }^{28}$ The most influencing 


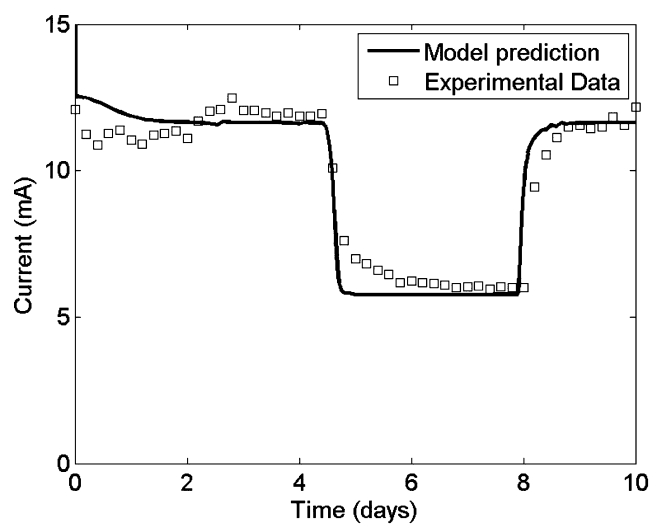

(A)

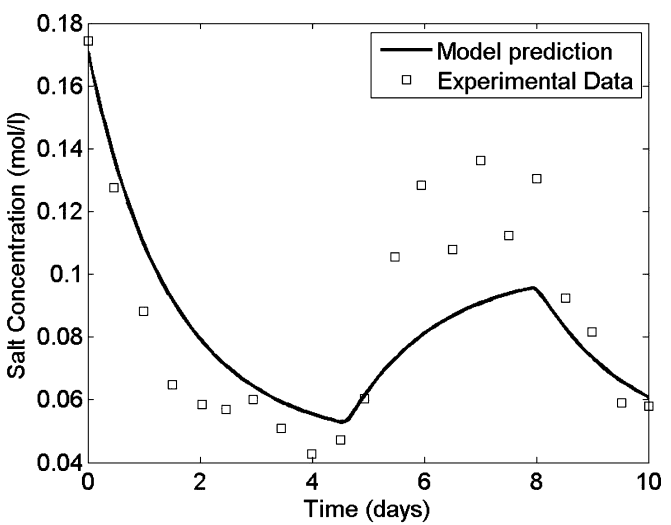

(B)

Figure 1. Experimental data and model simulation when the anode influent feeding rate was changed from 0.5 to 0.2 , and then back to $0.5 \mathrm{~mL}$. $\min ^{-1}$ : (A) current generation and (B) effluent salt concentration.

parameters have the priority to be re-estimated. Thus, sensitivity analysis, one of the most commonly used technique for parameter selection, ${ }^{29}$ was conducted to quantify the influence of each model parameter on the dynamics of the MDC current and the salt concentration.

The sensitivity measure $s_{i, j}$ is typically defined by eq 18 , in which the partial derivative of the output $y_{j}$ over parameter $p_{i}$ is normalized by the nominal values of $p_{i}$ and $y_{j}$ (i.e., $p_{i}{ }^{0}$ and $y_{j}{ }^{0}$, respectively).

$$
S_{i, j}=\left.\frac{p_{i}^{0} \partial y_{j}}{y_{j}^{0} \partial p_{i}}\right|_{\mathbf{P}_{0}}
$$

where the vector $P_{0}$ is a vector of nominal values of all the parameters in the model.

This work employed local sensitivity analysis, in which only one parameter is changed at one time while other parameters are fixed at their nominal values. The steady states of current and salt concentration were defined as the output vector, i.e., $\mathrm{Y}$ $=\left[I_{\mathrm{MDC}} C_{\text {salt } \mathrm{m} m}\right]$. Parameter $p_{i}$ was changed to $p_{i}{ }^{0}+\Delta p_{i}$, and the steady states of $I_{\mathrm{MDC}}$ and $C_{\text {salt,m }}$ were quantified from the simulation and used to construct the output vector $Y$, which was compared to its nominal value $Y^{0}$. Equation 18 is reorganized as follows:

$$
s_{i, j}=\left.\frac{p_{i}^{0}\left[\operatorname{norm}(Y)-\operatorname{norm}\left(Y^{0}\right)\right]}{\operatorname{norm}\left(Y^{0}\right) \Delta p_{i}}\right|_{\mathrm{P}_{0}}
$$

Equation 19 was applied to quantify another sensitivity measure $s_{i j j}$ for the scenario where parameter $p_{i}$ was changed to $p_{i}^{0}-$ $\Delta p_{i}$. In this sensitivity analysis, each parameter was increased or decreased by one magnitude. The sum of the absolute values of the two sensitivity values $s_{i j}$ for parameter $p_{i}$ (i.e., decreased and increased by $\Delta p_{i}$ ) was used to present the impact of this parameter on the change of current and salt concentration.

Parameter Estimation. The parameters selected by sensitivity analysis were further re-estimated from experimental data. Genetic algorithm routine in MATLAB was used for parameter estimation to minimize the relative root-mean-square error (eq 20) between the predicted value and the experimental data. Unlike typical nonlinear least-squares approaches, which generally return local optimal solutions, genetic algorithm can find the global optimal solution with moderate searching efficiency. This method mimics the natural processes of fitness- based selection for the best-adapted individuals and species from among their competitors.

$$
\operatorname{RMSR}=\frac{\sqrt{\frac{\sum_{i=1}^{N}\left(y_{i}-\hat{y}_{i}\right)^{2}}{N}}}{\max (\hat{y})}
$$

where $N$ is the total sampling time points in the simulation; $\hat{y}_{i}$ and $y_{i}$ represent experimental data and model predicted values at $t_{i}$, respectively. The maximum value of the experimental data for the current and the salt concentration were used to normalize the error in eq 20 such that the relative root-meansquare error (RMSR) is a direct measure of the discrepancy between the experimental data and the estimated value. A small RMSR indicates a good fit of the model to the data.

\section{RESULTS AND DISCUSSION}

Model Fitting. All the parameters were tested in the sensitivity analysis, and the parameters were ranked on the basis of their sensitivity measure values. The impact from the initial values of the two microorganism concentrations was also evaluated. Thus, those two initial values were also regarded as changeable parameters. The parameters with the top 10 sensitivity values are listed in a descending order (SI Table $\mathrm{S} 1$ ). The sensitivity measures were normalized by the largest sensitivity value (i.e., the value for parameter $k_{\mathrm{r}}$ ) to show the relative difference among these values. It was found that parameter $k_{\mathrm{r}}$ had a much larger impact on the MDC current and the salt concentration than other parameters. This can be explained by eqs 13 and 15 in which $k_{\mathrm{r}}$ is an important parameter that correlates the anodophilic microorganism concentration with the internal electrical resistance and the open circuit voltage. The sensitivity measures for other parameters are relatively small, possibly because of the fact that sensitivity analysis heavily depends on the initial guessed values of parameters, and the selected nominal values of model parameters constrain the MDC performance from variation with those parameters other than $k_{r}$. In other words, the sensitivity measure can be changed if the nominal values of model parameters change, which was confirmed by multiple simulates. Interestingly, the parameters listed in SI Table S1 were still ranked top for their influence on the MDC current and salt concentration. Therefore, these parameters were good candidates for re-estimation. Among these parameters, $V_{\min }$ and $R_{\max }$ were determined directly from experiment measure. Other 


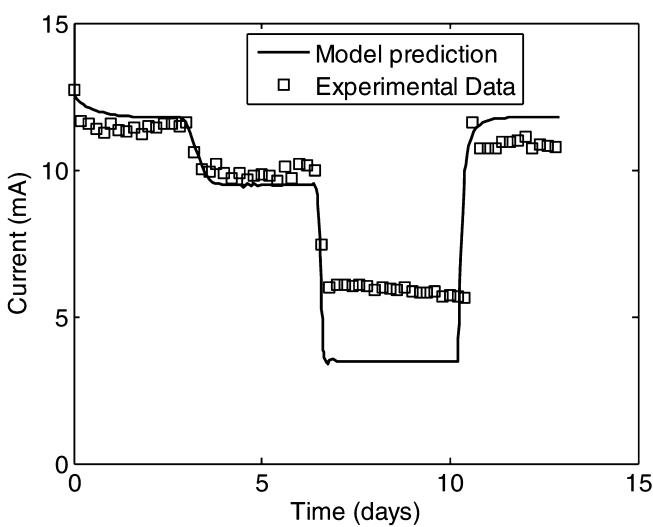

(A)

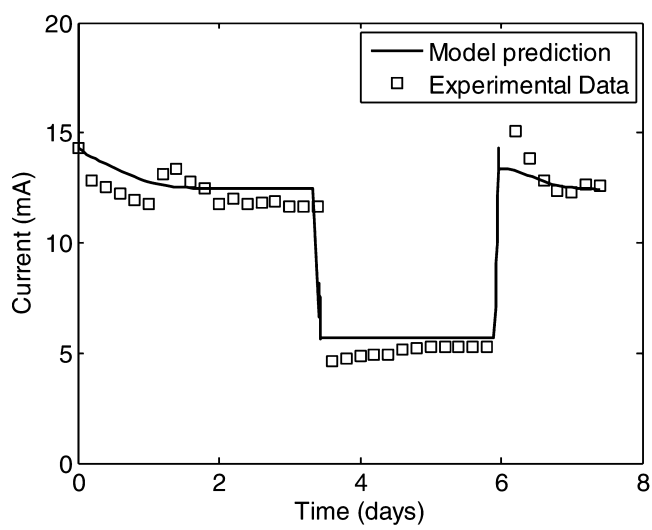

(C)

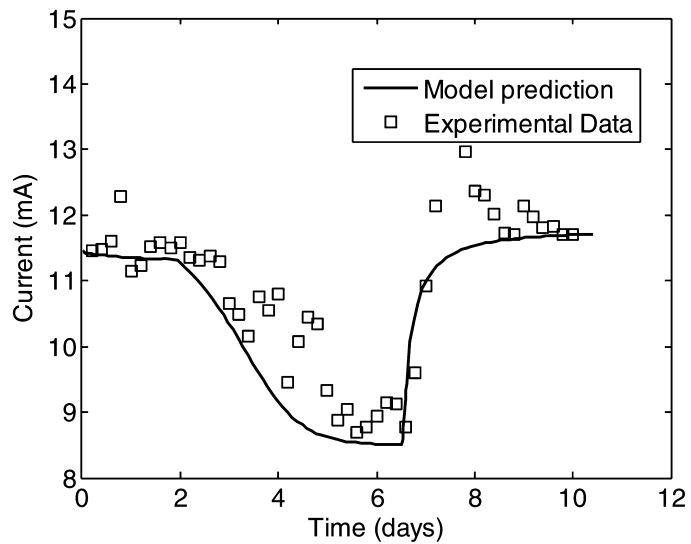

(E)

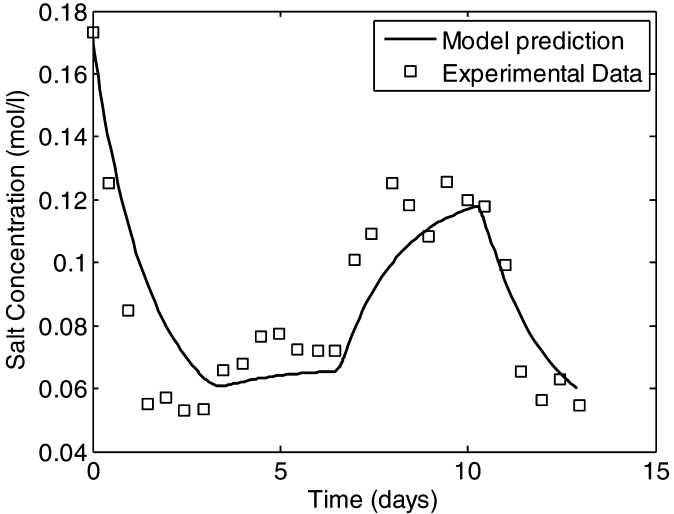

(B)

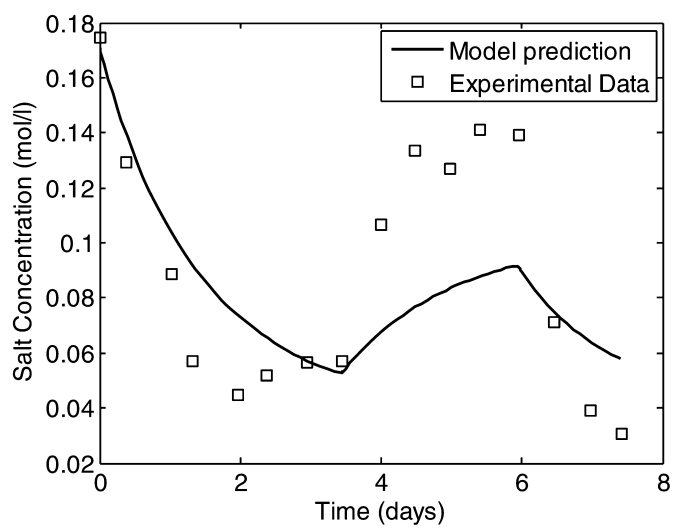

(D)

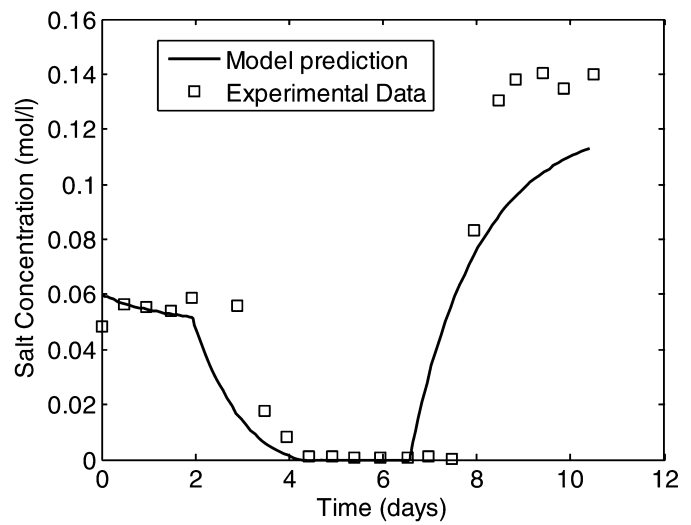

(F)

Figure 2. Model fitting under three different testing conditions: (A) current generation, and (B) effluent salt concentrations, when the concentration of acetate was changed from 1 to $0.6,0.2$ and then back to $1 \mathrm{~g} \cdot \mathrm{L}^{-1}$; (C) current generation, and (D) effluent salt concentrations, when the external resistances were changed from 0.1 to 100 , and then back to $0.1 \Omega$; (E) current generation, and (F) effluent salt concentrations, when the salt concentration was changed from 10 to 5 , and then back to $15 \mathrm{~g} \cdot \mathrm{L}^{-1}$.

than these two, the five most important parameters, including $k_{\mathrm{r}}$, the membrane salt transfer coefficient $d$, the mediator yield $Y_{\mathrm{M}}$, the maximum microorganism growth rate $k_{\mathrm{a} \text {,max }}$ and the initial concentration of anodophilic microorganism $C_{a}(0)$, were selected for re-estimation. They were estimated to be $0.082 \mathrm{~L}$.

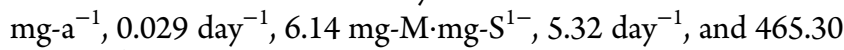
$\mathrm{mg}-\mathrm{a} \cdot \mathrm{L}^{-1}$ respectively. The values of other parameters are listed in SI Table S2.

The data used for parameter estimation were obtained by the following experimental conditions: the MDC was operated under a dynamic anolyte influent flow rate, which was changed from 0.5 to 0.2 , and then back to $0.5 \mathrm{~mL} \cdot \mathrm{min}^{-1}$. During the experiment, the change of each influent flow rate was made after the system had reached steady state. The predicted current and salt concentrations were plotted along with the experimental data in Figure 1A,B, which shows that the electrical current decreased from 12 to $6 \mathrm{~mA}$ when the influent acetate rate was reduced from 0.5 to $0.2 \mathrm{~mL} \cdot \mathrm{min}^{-1}$, and once the influent flow rate was increased back to $0.5 \mathrm{~mL} \cdot \mathrm{min}^{-1}$ the current increased close to the previous level (around $11 \mathrm{~mA}$ ). The initial salt solution $\left(0.170 \mathrm{~mol} \cdot \mathrm{L}^{-1}\right)$ was gradually desalinated to $0.060 \mathrm{~mol} \cdot \mathrm{L}^{-1}$ in 4 days. When the anode 


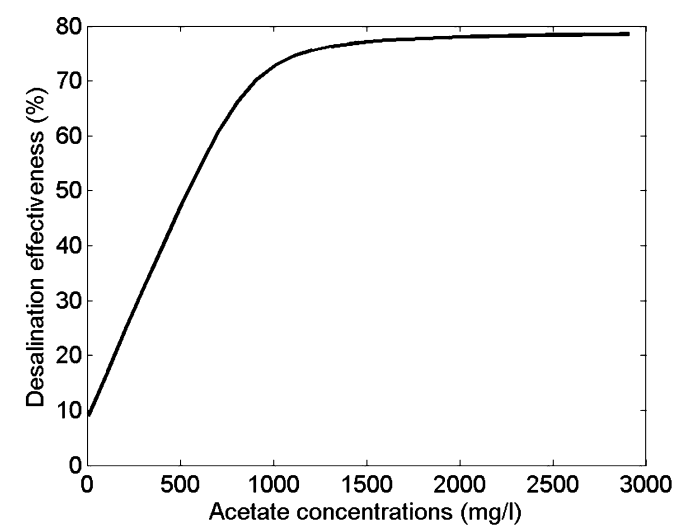

(A)

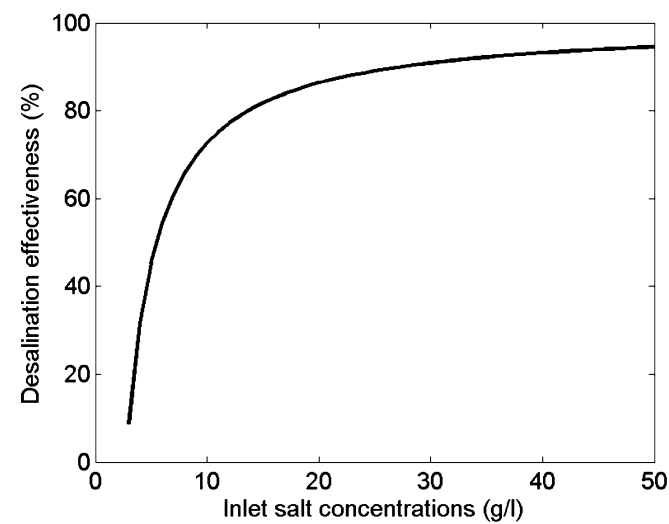

(C)

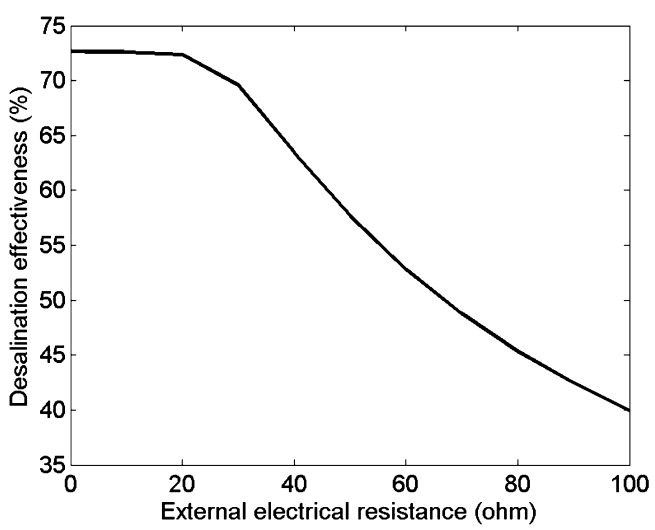

(E)

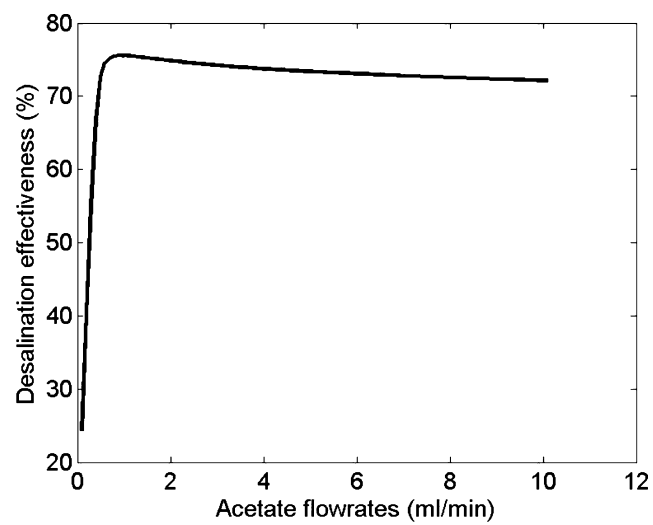

(B)

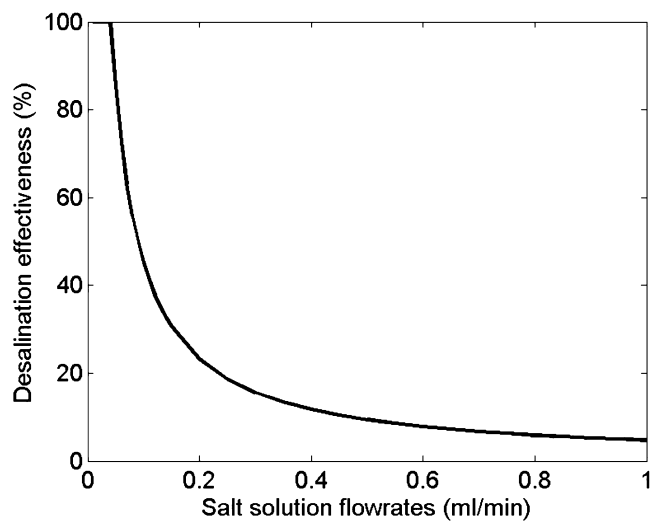

(D)

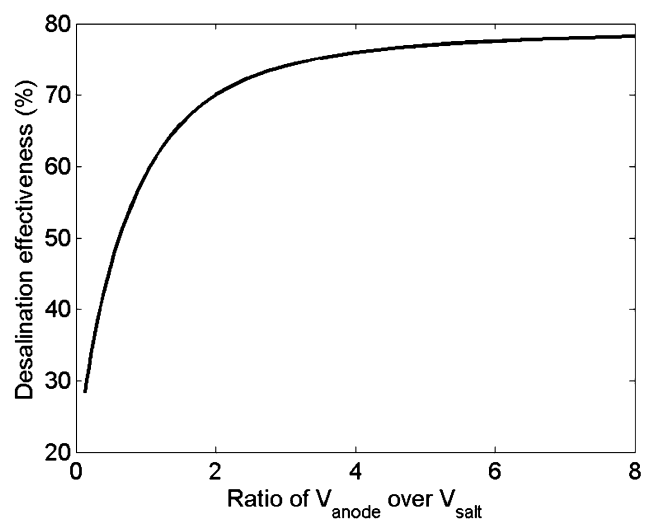

(F)

Figure 3. Model prediction with one variable parameter: (A) acetate concentrations; (B) acetate flow-rates; (C) influent salt concentrations; (D) salt solution flow rates; (E) external electrical resistance; and (F) ratios of volumes $V_{\text {anode }}$ and $V_{\text {salt }}$ in the MDC.

influent flow rate decreased, the resulting low current weakened the desalination efficacy, and caused the effluent $C_{\text {salt,m }}$ increasing to $0.120 \mathrm{~mol} \cdot \mathrm{L}^{-1}$. However, the efficient desalination was restored within 2 days when the anode influent rate was increased back to $0.5 \mathrm{~mL} \cdot \mathrm{min}^{-1}$. The model output of current value shows satisfactory agreement with the experimental measurement, and the relative root-mean-square error (RMSE) shows that the mean error for the current and salt concentration were within $6.97 \%$ and $12.12 \%$ of their maximum values. However, some overestimation/underestimation can be seen from the modeled variation trend of the effluent salt concentration as shown in Figure 1B. The predicted salt profile matches the experimental data better when the current was of a large value, despite some underestimation of salt removal. The overestimation of the salt removal mainly happens for the low current region (low anode influent rate). In the model, it was assumed that every electron would pull out a salt ion, but in reality it might not happen ideally, thereby resulting in the overestimation of the desalination efficiency.

The model is also able to predict the dynamics of the other outputs, i.e., the anode effluent acetate concentration $(S)$, the concentration of anodophilic microorganisms $\left(C_{\mathrm{a}}\right)$, the concentration of methanogenic microorganisms $\left(C_{\mathrm{m}}\right)$ and the oxidized mediator fraction $\left(M_{\mathrm{OX}}\right)$ (SI Figure S2). The substrate concentration in the effluent was clearly affected by the anolyte influent rate, which also influenced the concentration of anodophilic microorganisms. When the remained acetate in the anode drops to $16 \mathrm{mg} \mathrm{L}^{-1}$ due to microbial consumption, 
which is much lower than the half-saturation concentrations for the methanogenic microorganisms $\left(80 \mathrm{mg} \mathrm{L}^{-1}\right)$, the concentration of methanogenic microorganisms began to decrease. The oxidized mediator fraction remained stable. It should be noted those simulated results provide some implication about the dynamics within the MDC and should be experimentally verified for more accurate prediction.

Model Validation. Three independent operation tests were carried out to evaluate the prediction capability of the developed MDC model for the change in the influent concentration of acetate, the external resistance, and the concentration of the salt solution. The operating parameters were kept the same except for the target parameter being studied in each test.

The first set of tests was performed by changing the influent concentration of acetate from 1 to 0.6 , to 0.2 , then back to $1 \mathrm{~g}$. $\mathrm{L}^{-1}$. In response to the changes, the electrical current decreased from 12 to 10 , to 6 and then back to around $11 \mathrm{~mA}$, and the model gives a good fit for the most part, with some deviation for the acetate concentration $0.2 \mathrm{~g} \cdot \mathrm{L}^{-1}$ (Figure 2A). Meanwhile, the experimental salt concentration decreased significantly from initial 0.175 to around $0.055 \mathrm{~mol} \cdot \mathrm{L}^{-1}$ when operated at the acetate concentration of $1 \mathrm{~g} \cdot \mathrm{L}^{-1}$ (Figure 2B). As the acetate concentration underwent a two-step decrease, the salt concentration first increased slightly to $0.075 \mathrm{~mol} \cdot \mathrm{L}^{-1}$ and then jumped up to about $0.130 \mathrm{~mol} \cdot \mathrm{L}^{-1}$. The salt concentration resumed to $0.055 \mathrm{~mol} \cdot \mathrm{L}^{-1}$ as the acetate concentration was increased back to $1 \mathrm{~g} \cdot \mathrm{L}^{-1}$. The salt concentrations predicted by the model in response to this test generally followed the trend of experimental salt concentrations, with some underestimation for the first period of desalination and slight overestimation of salt removal ability at the low substrate supply period. The relative RMSE for the current and salt profiles were $12.08 \%$ and $9.01 \%$, respectively.

The second dynamic test was performed by varying the external resistance from 0.1 to 100 and then back to $0.1 \Omega$ (Figure 2C,D). The experimental current responded rapidly and decreased significantly as the external resistance was increased to $100 \Omega$. The model predicted the current values fairly well with slight overestimation and a low relative RMSE of $8.87 \%$. The experimental salt concentration responded to the decreased current within a day and increased gradually. When the external resistance was decreased to $0.1 \Omega$ again, the salt concentration started to decrease. Although the modelpredicted salt profile showed similar dynamic trend as the experimental data, the relative RMSE showed a high error of $17.57 \%$ for the salt profile, which mainly came from the low current region (high external resistance) where the assumption that one electron pulls out one salt ion might fail.

The third dynamic test was performed by varying the influent salt concentration from 10 to 5 and then up to $15 \mathrm{~g} \cdot \mathrm{L}^{-1}$. Both current generation and final salt concentration responded to the variation of initial salt concentration (Figure 2E,F). In general, the model presented a tight fit to the current data with a relative RMSE of $5.81 \%$. The model also predicted fairly accurate steady state salt concentration, with some overestimation of salt removal at the very beginning of each change. The relative RMSE for the salt profile was $16.14 \%$, which mainly came from the mismatch with the salt concentration in the last few time points. The delay for the modeled salt concentration to reach steady state might be responsible for the discrepancy.
Model Prediction: One Parameter Variation. The validated MDC model can predict the dynamics of current and salt concentration with reasonable accuracy for three different experimental conditions and is of great value as an in silico platform to investigate optimal operation parameters. Herein, the effectiveness of desalination in the MDC, which is defined as the difference of salt concentration between the influent and the effluent normalized by the influent salt concentration, is evaluated for various values of operating parameters including influent acetate concentrations and flow rates, influent salt concentrations and flow rates, external electrical resistance, and volumes of the anode and salt compartments.

In this section, only one design parameter is changed at each time to determine the parameter value that optimizes the desalination performance of the MDC. Figure 3A shows the effectiveness of desalination affected by acetate concentration that is gradually changed from 10 to $2900 \mathrm{mg} \cdot \mathrm{L}^{-1}$. The inflection point, below which corresponds to the largest slope in the curve, suggesting that the effectiveness has limited increase after the acetate concentration increases above 950 $\mathrm{mg} \cdot \mathrm{L}^{-1}$. Similarly, the acetate flow rate is varied from 0.1 to 15 $\mathrm{mL} \cdot \mathrm{min}^{-1}$, as shown in Figure 3B. The optimal acetate flow rate is determined to be $0.8 \mathrm{~mL} \cdot \mathrm{min}^{-1}$ based on the inflection point. Excessive acetate cannot be further oxidized by microorganisms and thus cannot contribute to improving desalination. Increasing acetate flow rate above $0.8 \mathrm{~mL} \cdot \mathrm{min}^{-1}$ has a slightly reducing effect to desalination effectiveness. It is expected that as the acetate flow rate keeps increasing, it will reach a so-called cell-washout point eventually, where no bacteria activity exists in the anode leading to no electrical-driven desalination.

The optimal salt influent concentration and flowrate is evaluated as shown in Figure 3C,D. The influent salt concentration is gradually changed from 3 to $50 \mathrm{~g} \cdot \mathrm{L}^{-1}$, and the desalination effectiveness increases until the inflection point, suggesting that the optimal influent salt concentration is around $13 \mathrm{~g} \cdot \mathrm{L}^{-1}$ (Figure $3 \mathrm{C}$ ). The increased salt concentrations provide more ions to the solution thus to make it more conductive and also increase the concentration gradient that facilitates the salt diffusion to other compartments. Further increasing influent salt concentration still improves the desalination effectiveness, but very slowly, as the capacity of an MDC to remove salt reaches a limit at this setting. The flow rate of saline water is varied from 0.01 to $1 \mathrm{~mL} \cdot \mathrm{min}^{-1}$ (Figure $3 \mathrm{D})$. The desalination effectiveness reaches $100 \%$ if the saline water flow rate is less than $0.04 \mathrm{~mL} \cdot \mathrm{min}^{-1}$, and increasing influent salt flow rate tends to reduce the desalination effectiveness. A faster salt influent flow rate leads to a shorter hydraulic retention time which in turn limits the desalination time of a certain amount of saline water.

The external electrical resistance is evaluated from 0.01 to $100 \Omega$, and the desalination effectiveness is graphed in Figure $3 \mathrm{E}$. The trend in the figure suggests that when the external resistance is higher than $30 \Omega$, the effectiveness starts to decrease significantly, because that larger external electrical resistance leads to smaller current in the MDC, and thus a lower driving force for the ion migration from the saline solution into other compartments. Reducing external resistance lower than $30 \Omega$ does not significantly change the current generated by the MDC, and thus maintains the desalination effectiveness around $70 \%$.

The optimal volume distribution in the anode and salt compartments is studied upon the constraint that the total 
volume of the anode compartment $\left(V_{\text {anode }}\right)$ and the middle desalination compartment $\left(V_{\text {salt }}\right)$ is kept constant at $450 \mathrm{~mL}$. The simulation is performed as the ratio of $V_{\text {anode }}$ over $V_{\text {salt }}$ increases from 0.125 to 8 (Figure $3 \mathrm{~F}$ ). Higher $V_{\text {anode }}$ to $V_{\text {salt }}$ ratios result in better desalination effectiveness. The inflection point in this curve indicates the optimal ratio of 2.5 , which corresponds to an anode compartment volume of $321 \mathrm{~mL}$. Further increasing the ratio of $V_{\text {anode }}$ over $V_{\text {salt }}$ does not further improve desalination. A larger anode compartment benefits the desalination, likely because of more current generation as a result of stronger anode microbial activities, and this was also demonstrated by the previous studies. For example, in a rectangular MDC, the desalination effectiveness exhibited a decreasing trend as the desalination compartment was enlarged and the optimal ratio of $V_{\text {anode }}$ over $V_{\text {salt }}$ was obtained around $2{ }^{14}$ The change in $V_{\text {anode }}$ and $V_{\text {salt }}$ may lead to the change in the areas of ion exchange membranes and the distance between the two ion exchange membranes. These changes can influence the amount of bacteria in the anode, as well as the solution resistance and the mass transfer in the anode and desalination chambers. To take into account the change especially regarding membrane area in the simulation for Figure $3 F$, substantial experiments need to perform to calibrate the change in the values of model parameters with the change in $V_{\text {anode }}$ and $V_{\text {salt }}$ and that will be a key task for future investigation. Nevertheless, the developed model is able to predict the desalination of a scaled up MDC (105 L) with a small relative error (i.e., 1.2\%) (SI Figures S3 and S4).

Model Prediction: Combined Parameters Variation. The combined effects were studied focusing on acetate flow rates, saline water flow rates, and external electrical resistance, where two design parameters were changed simultaneously for evaluating the desalination effectiveness. The simulation performed by varying different combinations of acetate flow rates and external electrical resistance shows that (1) for a fixed external electrical resistance, the desalination effectiveness increases upon the increase of acetate flow rate up to 0.8 $\mathrm{mL} \cdot \mathrm{min}^{-1}$; (2) for a fixed acetate flow rate (lower than $0.8 \mathrm{~mL}$. $\left.\mathrm{min}^{-1}\right)$, the desalination effectiveness increases upon the decrease of the external electrical resistance (Figure 4A). These observations are consistent with the profiles shown in Figure 3B,E. For the region where the external resistance is lower than $30 \Omega$ and the acetate flow rate rises higher than 0.8 $\mathrm{mL} \cdot \mathrm{min}^{-1}$, nearly constant high desalination effectiveness is observed, suggesting the optimum operation.

The effects of different combinations of salt flow rates and external electrical resistance is shown in Figure 4B. A higher salt solution flow rate (within the range of $\sim 0.2 \mathrm{~mL} \cdot \mathrm{min}^{-1}$ ) can be compensated by reducing external resistance. While as the salt solution flow rate gets very close to $0 \mathrm{~mL} \cdot \mathrm{min}^{-1}$, the external resistance has much smaller effect on desalination effectiveness because a long hydraulic retention time makes it possible for all the ions to be removed out of salt solution as long as the system is under a closed-circuit condition. The salt solution flow rate higher than $0.2 \mathrm{~mL} \cdot \mathrm{min}^{-1}$ results in overall low desalination effectiveness, and the effect of reducing external resistance is indistinguishable, because the increase in salt removal is negligible in comparison to the large amount of salt in the solution.

The simulation was also performed by varying different combinations of acetate flow rates and salt solution flow rates (Figure 4C). In the region of acetate flow rate lower than 0.8 $\mathrm{mL} \cdot \mathrm{min}^{-1}$, the desalination effectiveness can be improved by

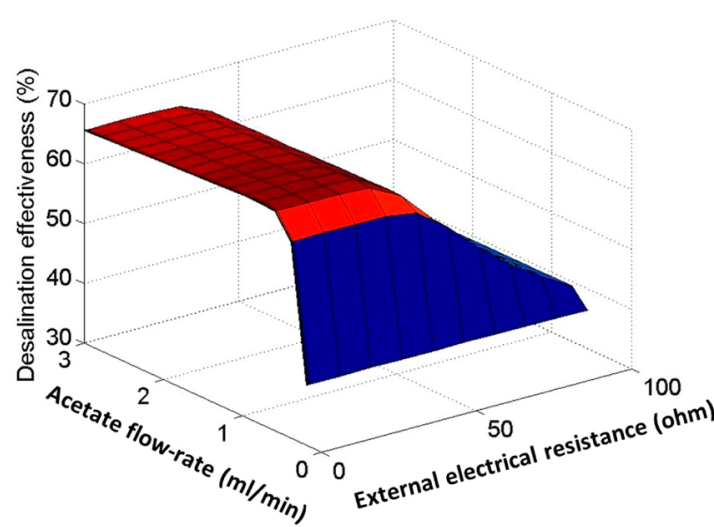

(A)

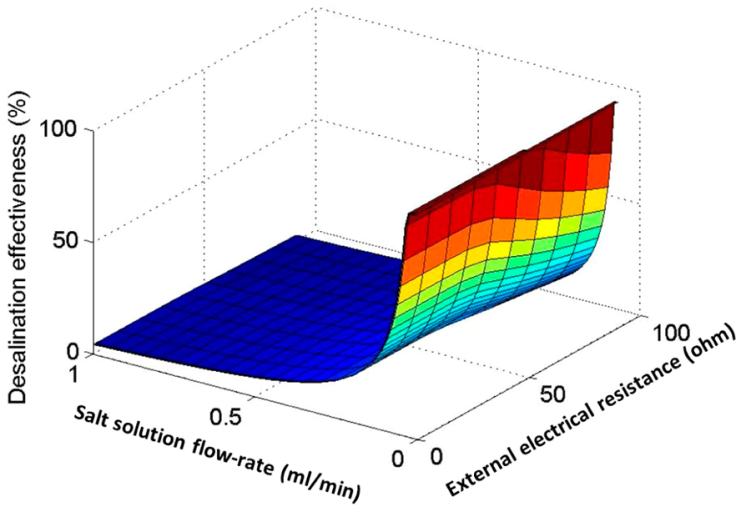

(B)

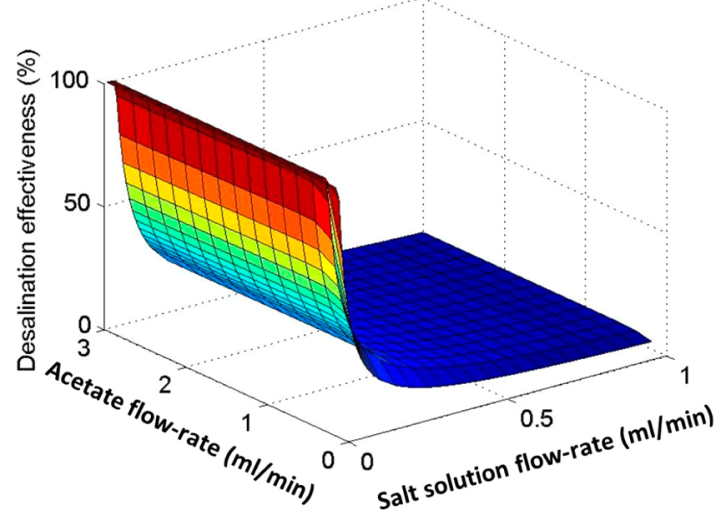

(C)

Figure 4. Model prediction with two variable parameters: (A) the combination of varying both acetate flow rate and external electrical resistance; (B) the combination of varying both salt solution flow rate and external electrical resistance; and (C) the combination of varying both acetate and salt solution flow rates.

reducing salt solution flow rate. Slower acetate supply leads to lower bacterial activity and thus less electron generation to produce current. Reducing the amount of salt addition in a specific amount of time is able to compensate for the low current and still keeps relatively high desalination effectiveness. The remarkable increment in desalination effectiveness by reducing slat solution flow rate is not observed if the salt solution flow rate is higher than $0.2 \mathrm{~mL} \cdot \mathrm{min}^{-1}$. Increasing acetate flow rate higher than $0.8 \mathrm{~mL} \cdot \mathrm{min}^{-1}$ does not help improve desalination effectiveness at a higher salt solution flow rate, possibly because no further improvement in microorganism-driven current generation occurs. 
Perspectives. This work represents the first attempt to model the desalination process in MDCs, and the results have some important implications to MDC development and encourage further development of the MDC model. According to the simulation data, we have developed our next-stage MDC system $(105 \mathrm{~L})$ with a ratio of $4: 1$ between the anode and the salt compartments (the performance data of the scaled MDC system will be presented in a separate publication). The model was able to well predict the current generation, organic concentration and salt removal rate in the large-scale MDC system (SI Figures S3 and 4). However, as the first MDC model, we expect limitations (e.g., the model may be limited by the present MDC configuration) and problems (e.g., discrepancy of salinity between simulated and experimental data), which will be addressed in further development.

The present model was based on a number of assumptions, which simplified model and avoided the intense computational load of the simulations, making it more suitable for real-time process control and optimization of MDC systems when compared to more complicated models that consider spatial heterogeneity. However, the simplification on the anode biofilm, such as that substrate concentration gradient and heterogeneous spatial distribution of microorganisms across the anode biofilm were not considered, does limit the model's ability in predicting the desalination behavior of MDCs when external resistances and salt concentrations deviate from their nominal values. Further improvement will consider both discretized biofilm and bulk liquid regions. The assumption that every electron would pull out a salt ion is a possible factor that may lead to discrepancies in predicting salt removal. Having a current-dependent factor (which needs to be experimentally determined) and considering dilution effects may improve the model prediction for salt removal.

A mathematical model has its boundary, because of conditions that the data were obtained for determining the key parameters. The present model was developed based on a bench-scale tubular MDC system, but it may also be adapted to describe other MDC systems through re-estimating some important model parameters that are listed in Tables S1 and S2 in the SI. Those parameters include $k_{\mathrm{r}}$, which correlates the internal resistance with the growth rate of anodophilic microorganisms that may change for different microorganism species and anolyte compositions used in the MDC system, and the membrane salt transfer coefficient $d$, which is related to the diffusion coefficient, the membrane surface area, the membrane thickness, and the anode volume. Other parameters, such as the maximum growth rate of anodophilic microorganism (i.e., $\left.k_{\mathrm{a} \text {,max }}\right)$, the initial concentration of anodophilic microorganism (i.e., $C_{a}(0)$ ) and the maximum attainable concentrations for anodophillic microorganism (i.e., $C_{a, \max }$ ), may be adjusted depending on the specific microbial community.

\section{ASSOCIATED CONTENT}

\section{S Supporting Information}

The schematic of tubular MDC, some simulation results, the results of model validation with the large-scale MDC system, and the key parameters for the model. This material is available free of charge via the Internet at http://pubs.acs.org.

\section{AUTHOR INFORMATION}

\section{Corresponding Authors}

*Phone: (610) 519-4848; fax: (610) 519-7354; e-mail: zuyi. huang@villanova.edu.
*Phone: (540) 231-1346; fax: (540) 231-7698; e-mail: zhenhe@vt.edu.

\section{Author Contributions}

"These authors contributed equally to this work.

\section{Notes}

The authors declare no competing financial interest.

\section{ACKNOWLEDGMENTS}

The authors would like to thank Dr. Boris Tartakovsky at National Research Council, Canada, for the information on parameter values in his MFC model, and the anonymous reviewers for their helpful comments. The modeling work was supported by Villanova University (Grant SRF-RSG 2170307252; VCASE seed Grants 420492 and 420265). The MDC experiment was supported by the Research Grant Award No. US-4455-11 from BARD, the United States-Israel Binational Agricultural Research and Development Fund.

\section{REFERENCES}

(1) Onda, K.; LoBuglio, J.; Bartram, J. Global access to safe water: accounting for water quality and the resulting impact on MDG progress. Int. J. Environ. Res. Public Health. 2012, 9 (3), 880-894.

(2) Semiat, R. Energy issues in desalination processes. Environ. Sci. Technol. 2008, 42 (22), 8193-8201.

(3) Cao, X.; Huang, X.; Liang, P.; Xiao, K.; Zhou, Y.; Zhang, X.; Logan, B. E. A new method for water desalination using microbial desalination cells. Environ. Sci. Technol. 2009, 43 (18), 7148-7152.

(4) Jacobson, K. S.; Drew, D. M.; He, Z. Efficient salt removal in a continuously operated upflow microbial desalination cell with an air cathode. Bioresour. Technol. 2011, 102 (1), 376-380.

(5) Zhang, B.; He, Z. Improving water desalination and wastewater treatment by hydraulically coupling an osmotic microbial fuel cell with a microbial desalination cell. J. Membr. Sci. 2013, 441, 18-24.

(6) Mehanna, M.; Saito, T.; Yan, J.; Hickner, M.; Cao, X.; Huang, X.; Logan, B. E. Using microbial desalination cells to reduce water salinity prior to reverse osmosis. Energy Environ. Sci. 2010, 3 (8), 1114-1120.

(7) Kim, Y.; Logan, B. E. Series assembly of microbial desalination cells containing stacked electrodialysis cells for partial or complete seawater desalination. Environ. Sci. Technol. 2011, 45 (13), 5840-5845.

(8) Jacobson, K. S.; Drew, D. M.; He, Z. Use of a liter-scale microbial desalination cell as a platform to study bioelectrochemical desalination with salt solution or artificial seawater. Environ. Sci. Technol. 2011, 45 (10), 4652-4657.

(9) Zhang, B.; He, Z. Energy production, use and saving in a bioelectrochemical desalination system. RSC Adv. 2012, 2, 1067310679.

(10) Kim, Y.; Logan, B. E. Series assembly of microbial desalination cells containing stacked electrodialysis cells for partial or complete seawater desalination. Environ. Sci. Technol. 2011, 45, 5840-5845.

(11) Luo, H.; Jenkins, P. E.; Ren, Z. Concurrent desalination and hydrogen generation using microbial electrolysis and desalination cells. Environ. Sci. Technol. 2011, 45, 340-344.

(12) Ping, Q. Y.; Cohen, B.; Dosoretz, C.; He, Z. Long-term investigation of fouling of cation and anion exchange membranes in microbial desalination cells. Desalination. 2013, 325, 48-55.

(13) Luo, H.; Xu, P.; Ren, Z. Long-term performance and characterization of microbial desalination cells in treating domestic wastewater. Bioresour. Technol. 2012, 120, 187-193.

(14) Ping, Q. Y.; He, Z. Effects of inter-membrane distance and hydraulic retention time on the desalination performance of microbial desalination cells. Desalin. Water Treat. 2013, 3, 1-8.

(15) Ping, Q. Y.; He, Z. Improving the flexibility of microbial desalination cells through spatially decoupling anode and cathode. Bioresour. Technol. 2013, 144, 304-310.

(16) Peng, S. K.; Liang, D. W.; Diao, P.; Liu, Y. Y.; Lan, F.; Yang, Y. H.; Lu, S. F.; Xiang, Y. Nernst-ping-pong model for evaluating the 
effects of the substrate concentration and anode potential on the kinetic characteristics of bioanode. Bioresour. Technol. 2013, 136, 610616.

(17) Picioreanu, C.; Head, I. M.; Katuri, K. P.; van Loosdrecht, M. C. M.; Scott, K. A computational model for biofilm-based microbial fuel cells. Water Res. 2007, 41, 2921-2940.

(18) Zeng, Y. Z.; Choo, Y. F.; Kim, B. H.; Wu, P. Modelling and simulation of two-chamber microbial fuel cell. J. Power Sources 2010, 195, 79-89.

(19) Pinto, R. P.; Srinivasan, B.; Manuel, M. F.; Tartakovsky, B. A two-population bio-electrochemical model of a microbial fuel cell. Bioresour. Technol. 2010, 101 (14), 5256-5265.

(20) Pinto, R. P.; Srinivasan, B.; Escapa, A.; Tartakovsky, B. Multipopulation model of a microbial electrolysis cell. Environ. Sci. Technol. 2011, 45, 5039-5046.

(21) Marcus, A. K.; Torres, C. I.; Rittmann, B. E. Conduction-based modeling of the biofilm anode of a microbial fuel cell. Biotechnol. Bioeng. 2007, 98 (6), 1171-1182.

(22) Marcus, A. K.; Torres, C. I.; Rittmann, B. E. Evaluating the impacts of migration in the biofilm anode using the model PCBIOFILM. Electrochim. Acta 2010, 55, 6964-6972.

(23) Picioreanu, C.; van Loosdrecht, M. C. M.; Curtis, T. P.; Scott, K. Model based evaluation of the effect of $\mathrm{pH}$ and electrode geometry on microbial fuel cell performance. Bioelectrochemistry. 2010, 78 (1), 824.

(24) Oliveira, V. B.; Simoes, M.; Melo, L. F.; Pinto, A. A 1D mathematical model for a microbial fuel cell. Energy. 2013, 61, 463471.

(25) Xiao, L.; Damien, J.; Luo, J.; Jang, H. D.; Huang, J.; He, Z. Crumpled graphene particles for microbial fuel cell electrodes. J. Power Sources. 2012, 208, 187-192.

(26) Angenent, L. T.; Sung, S. Development of anaerobic migrating blanket reactor (AMBR), a novel anaerobic treatment system. Water Res. 2001, 35, 1739-1747.

(27) Stein, N. E.; Hamelers, H. V. M; Buisman, C. N. J. Stabilizing the baseline current of a microbial fuel cell-based biosensor through overpotential control under non-toxic conditions. Bioelectrochemistry 2010, 78 (1), 87-91.

(28) Grady, C. P. L. Jr., Daigger, G. T., Love, N. G., Filipe, C. D. M. Biological Wastewater Treatment, 3rd, ed.; CRC Press: Boca Raton, FL, 2011.

(29) Huang, Z. Y.; Chu, Y. F.; Hahn, J. Model simplification procedure for signal transduction pathway models: An application to IL-6 signaling. Chem. Eng. Sci. 2010, 65 (6), 1964-1975. 